ECCOMAS

Proceedia
M. Papadrakakis, M. Fragiadakis (eds.) Rhodes Island, Greece, 15-17 June 2017

\title{
FINITE ELEMENT ANALYSIS OF EXTERNAL RC WIDE BEAM- COLUMN JOINTS PROVIDED WITH DIFFERENT DETAILING SOLUTIONS
}

\author{
Giuseppe Santarsiero ${ }^{1}$ and Angelo Masi $^{1}$ \\ ${ }^{1}$ University of Basilicata \\ via dell'Ateneo Lucano, 10, Potenza, Italy \\ \{giuseppe.santarsiero, angelo.masi\}@unibas.it
}

Keywords: wide beam-column joints, cracking, seismic performance, nonlinear analysis, finite element models.

\begin{abstract}
Wide beams are part of the residential buildings' construction habits in Italy as well as in other Mediterranean countries. In fact, undoubted advantages are provided by this type of beams with respect to architectural functionality and time-saving in formwork installation. However, in the design process of new RC buildings, some penalties in terms of ductility are prescribed in seismic codes when this type of beam is used. Previous studies demonstrated that the detailing of beam reinforcement can influence the response of external wide beam-column connections, especially for what concern the reinforcing bars bent outside the column width. In order to investigate the influence of this aspect on the global performance of external wide beam-column joints, the authors calibrated detailed finite element models based on the experimental results of cyclic tests carried out on two full-scale specimens. Beyond the detection of the main phenomena characterizing the subassemblages' behavior, a parametric analysis has been performed to evaluate the influence of reinforcement amounts placed inside and outside the column core. Particularly, three values of the beam reinforcement area have been considered either placed inside or outside the column core, and the corresponding global lateral response curves of the beam-column joint have been obtained. It has been observed that in the cases where the additional amount of longitudinal reinforcement in the beam was placed inside the column core, both a more ductile behavior and a higher strength of the connection were obtained. This finding suggests that slip phenomena and torsion cracking occurred in the non-confined zone outside the column core, accounted for by the numerical model, can heavily influence the seismic behavior of this kind of beam-column joints even though they are seismically designed.
\end{abstract}

(C) 2017 The Authors. Published by Eccomas Proceedia.

Peer-review under responsibility of the organizing committee of COMPDYN 2017.

doi: $10.7712 / 120117.5699 .17312$ 


\section{INTRODUCTION}

The capacity to reduce emergency impact on communities due to seismic events [1] is strongly based on the prevention of collapse of both private and public buildings. This requires careful seismic assessments of the existing buildings as well by enhancing the seismic design of the new ones. The present study is aimed at characterizing the seismic behavior of beamcolumn connections equipped with wide beams (wide beam-column joints). This kind of beam is frequently used in the Italian and Mediterranean building stock both for older and newly designed buildings, especially for the residential ones.

This study is based on a remarkable experimental campaign carried out at the laboratory of structures of the University of Basilicata, where a set of wide beam-column joint specimens were tested under reversed cyclic lateral loads to study their seismic behavior $[2,3]$ and possible strengthening techniques [4]. Beam-column joints equipped with deep beams were part of the same research program $[5,6,7]$. Based on the results of the experimental tests on wide beam-column joints, the authors calibrated a detailed finite element model in order to perform a parametric analysis to evaluate the influence of some detailing solutions on the seismic behavior of joints. A software package able to appropriately account for the nonlinear properties of concrete, like cracking and crushing, as well as the reduction of shear and compressive strength after cracking, has been used in setting up the models $[8,9,10]$. Moreover, appropriate bond laws have been considered at the interface between concrete and steel to account for possible slippage phenomena [11]. The model, properly calibrated, allowed to understand the main damage mechanisms influencing the seismic performance of wide beam-column joints. In fact, bond slips of beam longitudinal reinforcement outside the column width is responsible for the limited contribution of these bars to the flexural capacity of the beam and, in turn, of the whole beam-column connection. Indeed, the beam bars bent outside the column core are not able to achieve the yielding stress. Contrarily, the internal ones reach the yielding stress and, additionally, are subjected to hardening better exploiting their tensile strength. Another key mechanism occurring in wide beam-column joints under cyclic loading is the cracking due to torsion in the beam width exceeding the column dimension. This is due to the pullpush effect of the beam bars outside the column and to the absence of confining reinforcement in that zone. As shown by the experimental results, this can lead to extensive damage and to the concrete cover spalling further decreasing the strength contribution of the beam external bars.

In order to obtain indications on the design of this kind of structural elements, a parametric analysis has been performed essentially by changing the amount of beam longitudinal reinforcement placed inside and outside the column core. It has been found that slip phenomena and torsion cracking occurred in the non-confined zone outside the column core, accounted for by the numerical model, are able to heavily influence the seismic behavior of this kind of beam-column joints even though they are seismically designed. The structural ductility is significantly influenced while minor changes are found for the maximum load value. This points out that the beam reinforcement in wide beams should not be evenly distributed along the width of the beam, but it should be placed prevailingly in the column core, where a better confinement condition is generally present, contrarily to the outer zones of the beam-column intersection. 


\subsection{EXPERIMENTAL CAMPAIGN}

The experimental program related to this study is reported in detail in [3]. However, for sake of clarity, a short summary is reported in the following. Cyclic quasi-static tests on deep and wide beam-column connections considered to belong to a four-storey residential RC building were included in the experimental program. Out of a total of 26 full-scale specimens, 12 were wide beam-column joints. They have different detailing but identical geometry. The reinforcement detailing was related to three different seismic design levels that is: i) no seismic design, ii) seismic design with respect to a design ground acceleration $a_{\mathrm{g}}$ for the Life Safety limit state equal to $0.25 \mathrm{~g}$, iii) seismic design with respect to a design ground acceleration $\mathrm{a}_{\mathrm{g}}$ for the Life Safety limit state equal to $0.05 \mathrm{~g}$. The subject of this study is a beamcolumn specimen having the latter seismic design level, i.e. with a low Earthquake Resistant Design level matching the seismic zone 4, being the less hazardous in Italy.

The details of the beam-column specimen under study and the test set-up are displayed in Fig. 1 and 2, respectively.

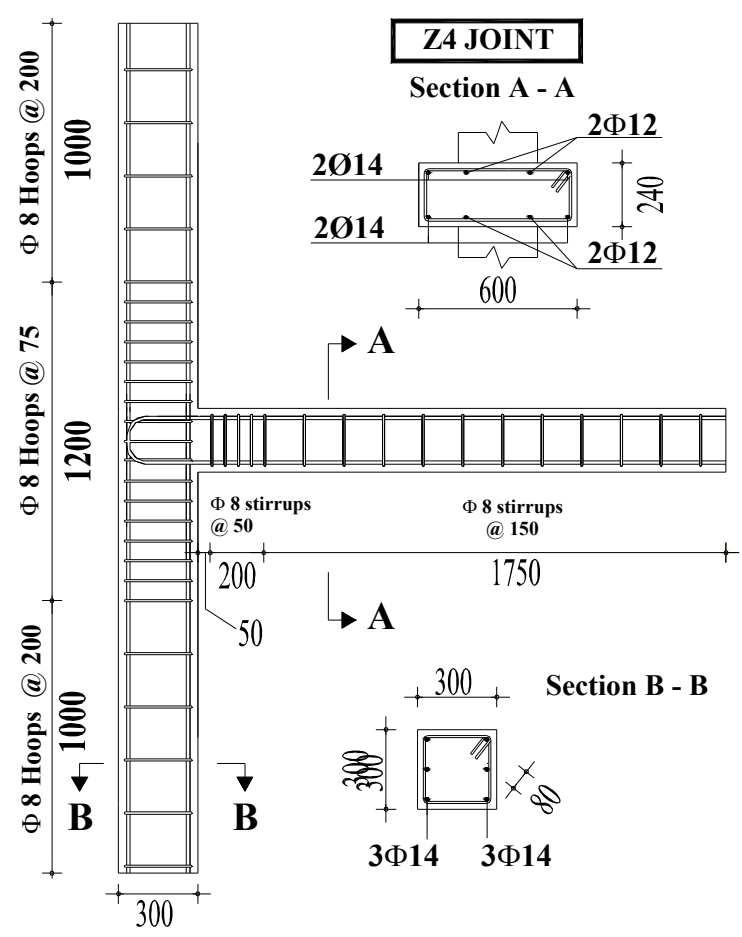

Figure 1: Geometry and detailing of the wide beam-column specimen under study.

The column in placed in vertical position so that an axial load can be applied to the column to simulate the upper storeys' dead load effect. A horizontal actuator is able to apply a lateral load to simulate the seismic effects in a cyclic quasi-static manner. The loading history was displacement controlled with $4 \mathrm{~mm} / \mathrm{s}$. A constant vertical load equal to $290 \mathrm{kN}$ was applied for the entire duration of the test. The specimen was equipped with several devices to measure both deformations and forces applied during the tests. Load cells were placed at the top of the column to record the horizontal force applied by the actuator as well as at the beam end to measure the reaction of the restraint made-up of steel strut. The top column displacement was acquired by means of a wire transducer, while the deformations at the beam-column intersection were acquired through Linear Variable Displacement Transducers (LVDT). More details on the instrumentation and test apparatus can be found in [3]. 


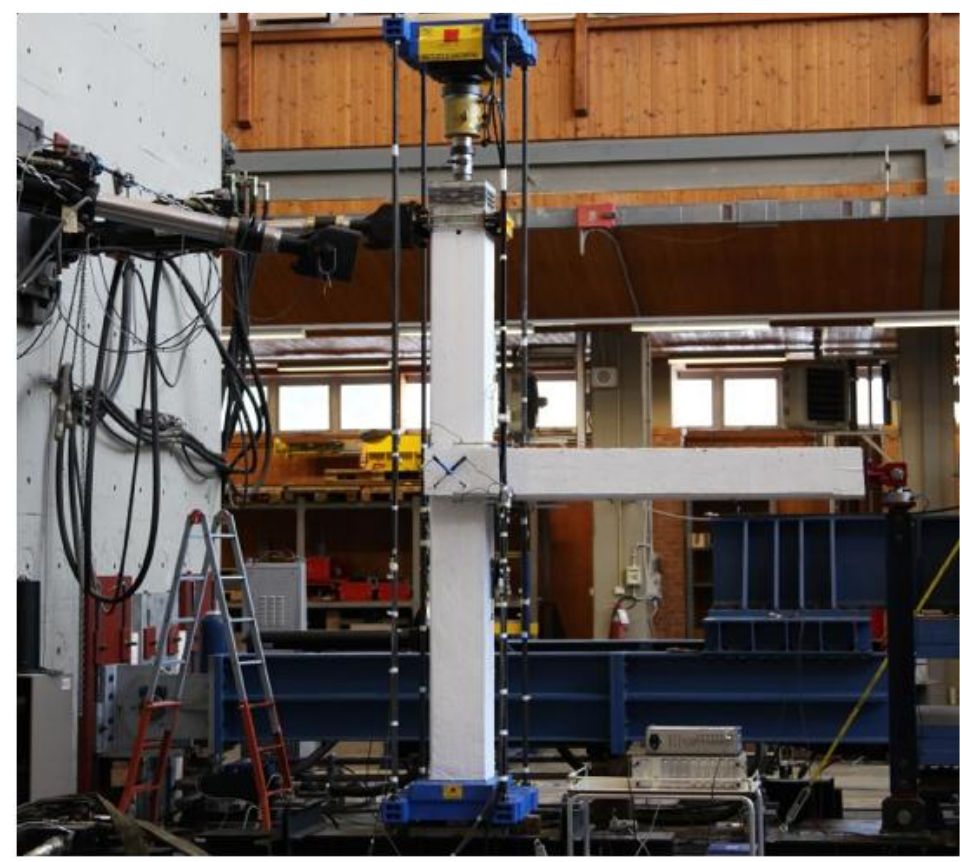

Figure 2: Test set-up.

\section{EXPERIMENTAL RESULTS}

The experimental behavior of a structural assemblage or member under cyclic loading is usually analyzed by plotting the envelope of all load-displacement curves obtained from the different tests carried out at increasing amplitude. In this case, the displacement has been normalized to the storey height $h$ of the building to which the specimen is supposed to belong. The interstorey height is $\mathrm{h}=3200 \mathrm{~mm}$ so that the drift values are computed as the ratio between the top column displacement and $h$.

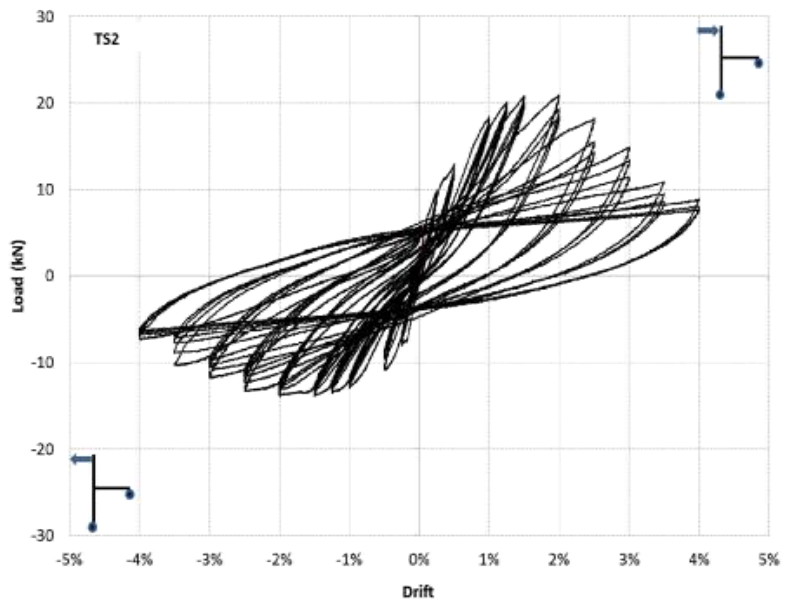

Figure 3: Load-drift envelopes.

As can be seen in Fig. 3 the maximum drift value attained during the test is $4 \%$. The maximum load is achieved at about $1.5 \%$ of drift both for positive and negative loading, attaining values of $20.96 \mathrm{kN}$ and $14.00 \mathrm{kN}$, respectively. Around $2 \%$ drift the load starts to decrease due to degrading phenomena. Making reference to the approach proposed by Panagiotakos 
and Fardis [12], the ultimate drift can be assumed as the value where a strength drop of $20 \%$ with respect to the maximum is observed. In this way, ultimate drift values equal to $2.7 \%$ and $3.2 \%$ have been computed for positive and negative loading, respectively.

This significant degrading effect is quite peculiar to this joint specimens and is related to the damage which develops near the intersection of beam and column, precisely at beam sides (see Fig. 4).

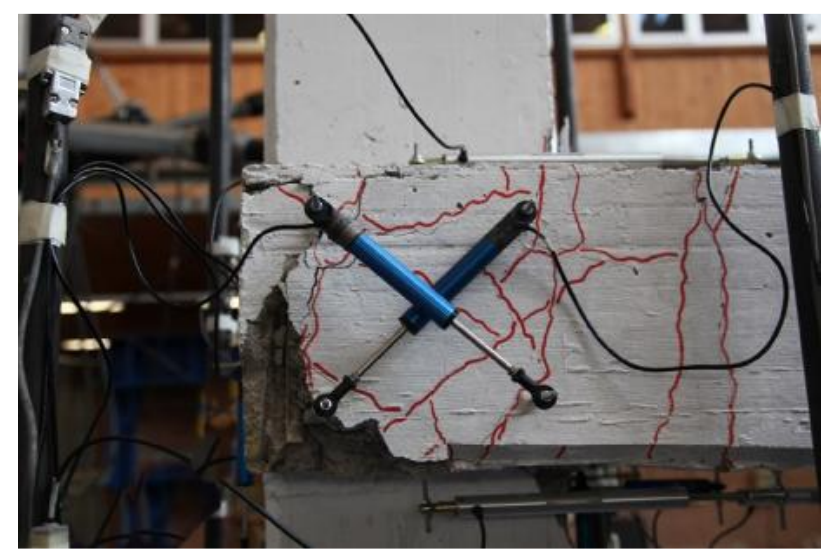

Figure 4: Cracking pattern at $4 \%$ drift.

Firstly, vertical cracks appeared at the beam-column intersection due to flexure. In the following stages of the test, inclined cracks developed at beam sides as can be seen in Fig. 4 . This is due to torsion stresses generated by the flexure transfer from the beam to the column. Moreover, the cracked zones at beam sides are not confined by stirrups as can be seen from Fig. 1. Indeed, column hoops confine only the column core, while the beam zones outside the column width are not confined despite some of the beam rebars are bonded there. Although the specimen under study is seismically designed, its cyclic behavior is not fully satisfactory. To better understand this behavior, a detailed finite element model using ATENA 3D software [8] is built and calibrated on the basis of the experimental results. Afterward, the model is used to perform a parametric analysis mainly aimed at evaluating the effect of different beam rebar arrangements on the whole subassemblage behavior.

\section{FEM MODELING}

Exploiting the experimental test results, a nonlinear finite element model developed with ATENA 3D software package [8] was developed. The software is based on the nonlinear fracture mechanics and, among its capabilities, there is the possibility to take into account the softening in compression as well as the tensile cracking of concrete. Moreover, the software incorporates different bond laws which can be applied to the steel reinforcement bars to take into account in a realistic way the bond slips between concrete and steel.

For the concrete, the robust smeared crack model was used. The main mechanical properties of the concrete, are as follows: $\mathrm{f}_{\mathrm{t}}=2.89 \mathrm{MPa}, \mathrm{f}_{\mathrm{c}}=37 \mathrm{MPa}, v=0.2$, and $\mathrm{E}_{\mathrm{c}}=32.5 \mathrm{GPa}$, being respectively the tensile strength, compressive strength, Poisson ratio and elastic modulus. Experimental tests on concrete cubes allowed to evaluate the compressive strength $f_{c}$ to which all other mechanical properties are related.

Compression stresses of concrete were simulated using a fictitious uniaxial model proposed by Chen \& Saleb [13] with a softening based on displacements. 


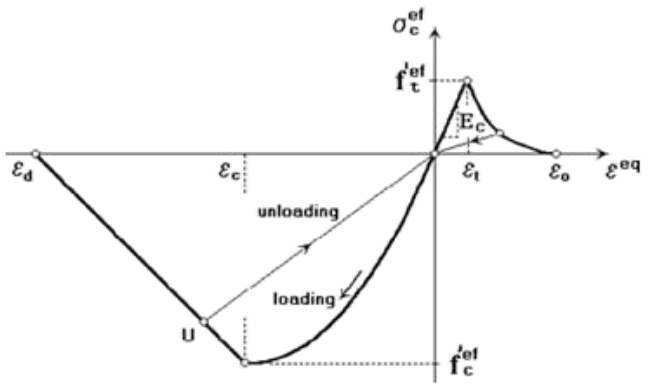

a)

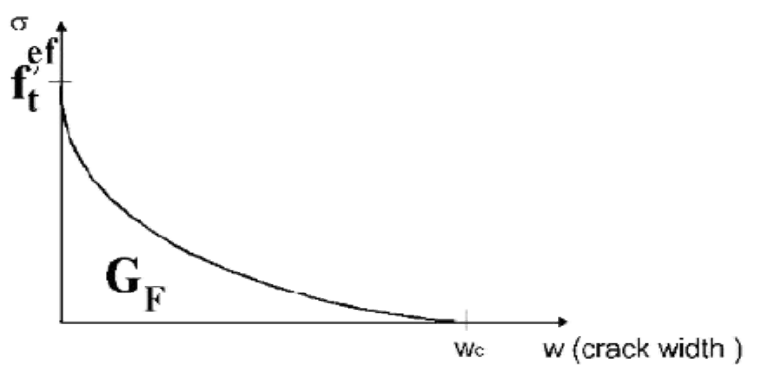

b)

Figure 5: a) Uniaxial compressive stress-strain law and b) crack opening law for tensile stresses for concrete.

The tensile behavior of concrete is ruled by the crack opening law (tensile stress vs crack opening displacement, see Fig. $5 b$ ) whose underlying area is the fracture energy $\left(\mathrm{G}_{\mathrm{F}}\right)$. The tensile strength drops with an exponential softening law. One of the most important parameters governing the tensile behavior is the fracture energy, that is the energy amount required to produce a crack of unit area. The fracture energy was computed by means of the Remmel's law [14]. Also, the tension stiffening effect was considered as related to the apparently stiffer tensile behavior of concrete due to the presence of steel reinforcement. A tension stiffening coefficient $\mathrm{C}_{\text {ts }}$ equal to 0.3 has been assumed, meaning that even when a crack is open a residual $30 \%$ tensile strength is considered.

An elastoplastic law with hardening was chosen for the reinforcing steel stress-strain relationship, with yielding stress $\mathrm{f}_{\mathrm{y}}=480 \mathrm{MPa}$ and failure stress $\mathrm{f}_{\mathrm{t}}=590 \mathrm{MPa}$. These values were based on experimental tests carried out on rebars belonging to the same steel supply used for the specimens' construction.

Regarding the simulation of the bond slip between concrete and steel, it has to say that, whereas in some cases a perfect connection could be considered, the experimental evidence drawn from the test under study shows that bond slip could contribute to the observed degrading phenomena. For this reason, the CEB-FIP Model Code (1990) bond law was adopted to account for the bond-slip behavior. Different laws were used depending on the bond and confining conditions of the beam rebars.

In particular, the bond law adopted for the bottom beam rebars outside the column width assumes unconfined concrete (no stirrups) and poor bond conditions (concrete cover size equal to $20 \mathrm{~mm}$ ). The resulting bond-slip law is depicted in Fig. 6, where the peak bond stress is $\tau_{\max }=5.38 \mathrm{MPa}$ and the residual one is $\tau_{f}=0.80 \mathrm{MPa}$. Critical slip values are $\mathrm{s}_{1}=\mathrm{s}_{2}=0.6 \mathrm{~mm}$ and $s_{3}=2.5 \mathrm{~mm}$, as reported in Tab. 3.1.1 of Model Code (1990) for splitting type bond failure.

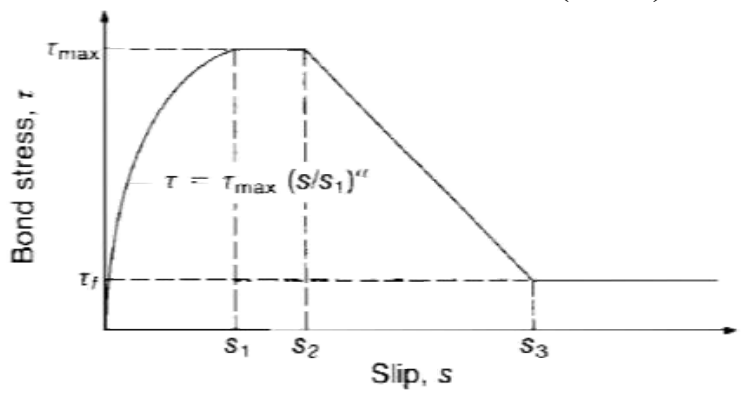

Figure 6: Bond-slip relationship.

Due to the presence of a concrete cover equal to $80 \mathrm{~mm}$, good bond conditions can be assumed for the upper beam bars placed outside the column core, with still unconfined concrete. This determines different values of bond stresses and bond slips, that is $\tau_{\max }=10.76 \mathrm{MPa}$, 
$\tau_{f}=1.6 \mathrm{MPa}, \mathrm{s}_{1}=\mathrm{s}_{2}=0.6 \mathrm{~mm}$ and $\mathrm{s}_{3}=1.0 \mathrm{~mm}$ (see Tab. 3.1.1 Model Code 1990, good bond conditions and splitting type bond failure). For all the other longitudinal rebars of the beam (placed within the column width), as well as for the column reinforcement bars, a perfect bond condition was assumed.

The global finite element model (see Fig. 7) is made-up of 5470 3D 8-node hexahedral volume elements with a size of $5.0 \mathrm{~cm}$ simulating the concrete volumes and the reinforcement bars were modeled through truss elements (i.e. capable of carrying only axial loads). The bars are embedded in the concrete, and the software is able to automatically create nodes shared by the truss elements and the hexahedral elements, thus contributing to adequately model the collaboration between steel and concrete. The finite element model was also provided with socalled monitoring points which give the model response at selected locations. Two monitoring points, located at the top of the column, where the displacement is applied, provide the column top displacement and the applied horizontal load values.
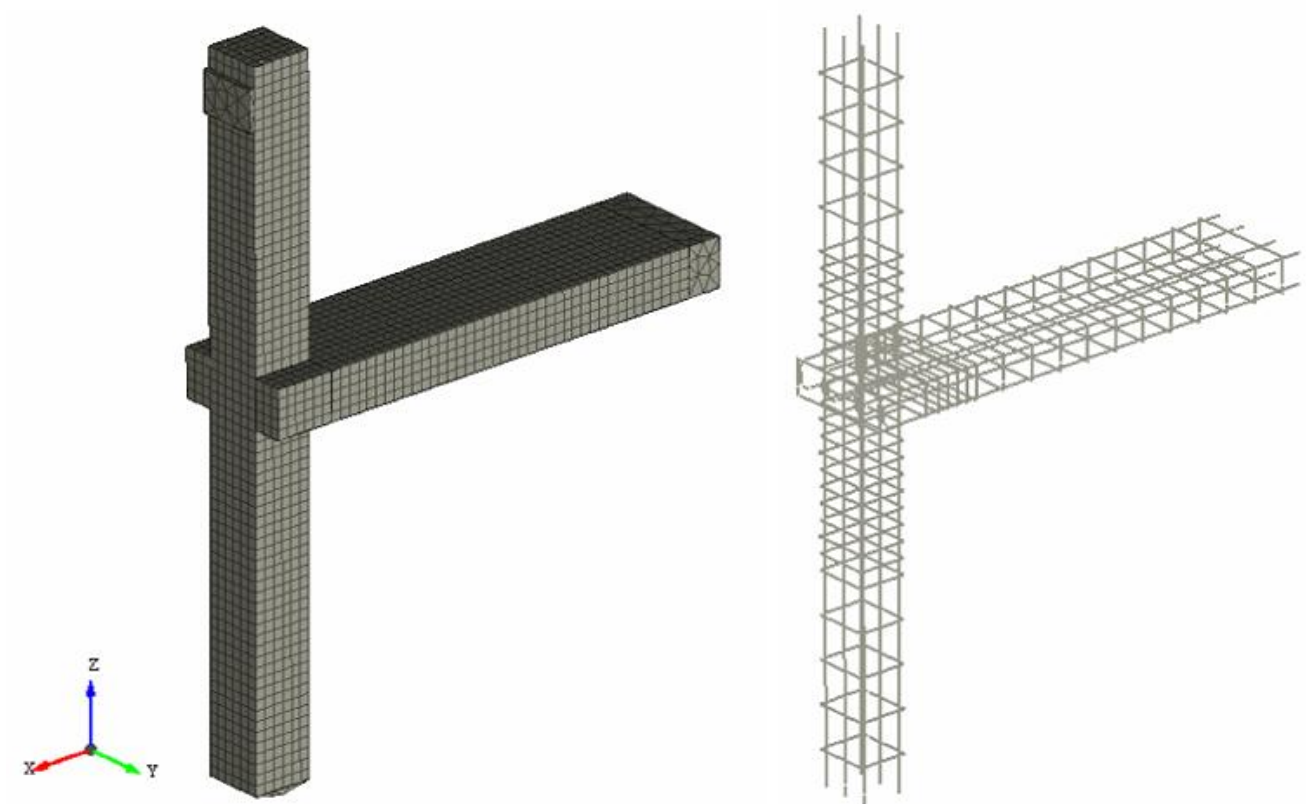

Figure 7: The concrete mesh of hexahedral elements and truss elements simulating the reinforcement.

\subsection{Comparison of numerical and experimental results}

The calibration of a nonlinear finite element model aims at reproducing the loaddisplacement curve, as good as possible, so evaluating whether the numerical simulations account for the main phenomena that characterize the experimental behavior and properly predict them [15]. 


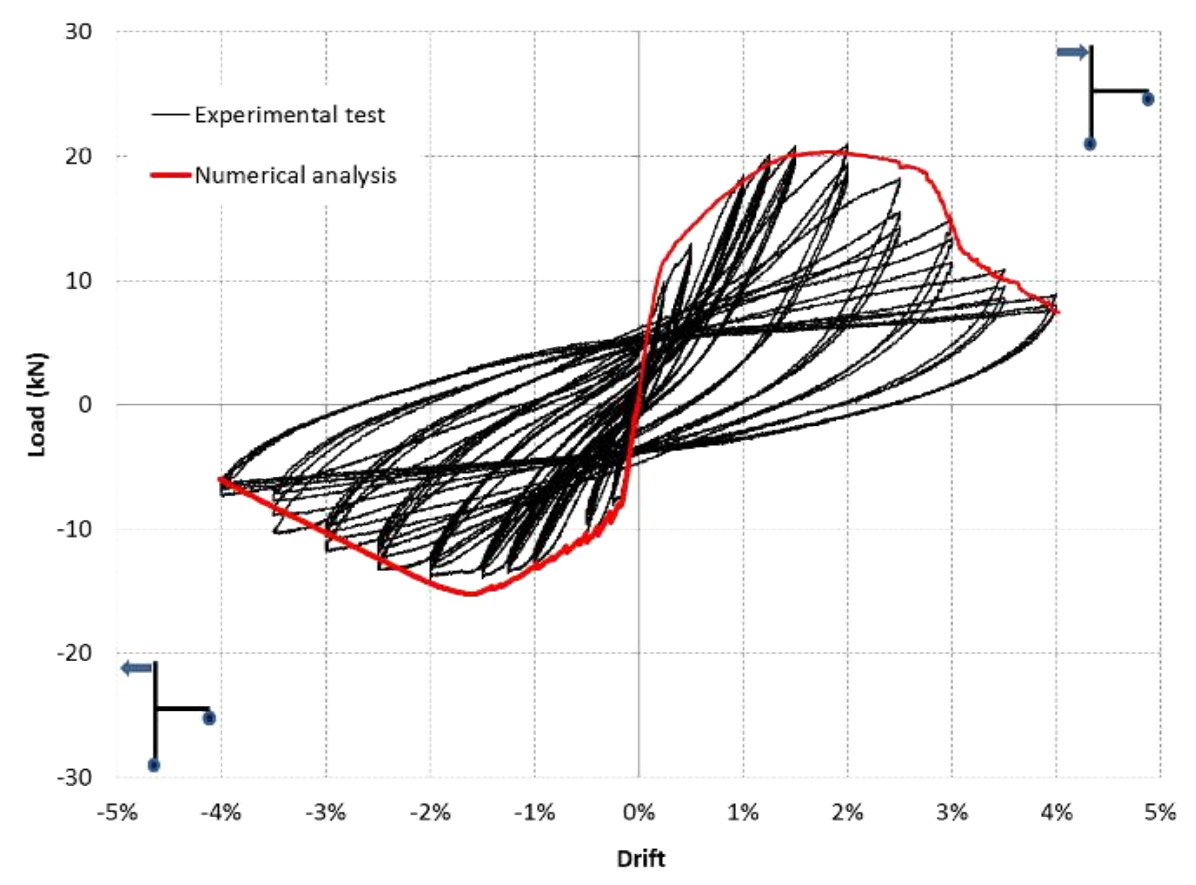

Figure 8: Comparison between numerical and experimental behavior.

First, it is worth noting that the performed numerical analyses were monotonic and not cyclic like in the test. For this reason, two separate steps of numerical analysis were necessary with respect to positive and negative loading. As can be seen in Fig. 8, the performed calibration process led to a numerical load-drift curve very close to the peak load values of the experimental envelope. This is observed through the entire drift range even when severe strength degradation effects occur. Fig. 9 depicts the experimental crack pattern at the end of the test and the related crack patterns obtained from the simulations under positive and negative loading. The comparison is satisfactory even though the monotonic numerical loading of the specimens yields necessarily different damage, at least in terms of crack sizes. However, from a qualitative point of view, numerical patterns show the presence of inclined cracks in the joint panel as well as vertical cracks at the beam-column intersection. The spalling effects at the end of the beam are not captured by the numerical model since is mainly due to the cyclic loading, not simulated by the numerical analysis.

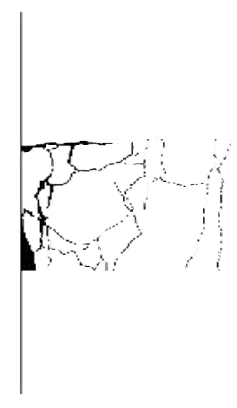

a)

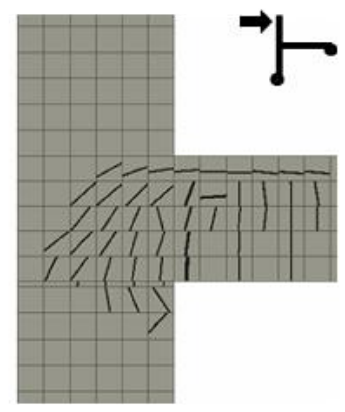

b)

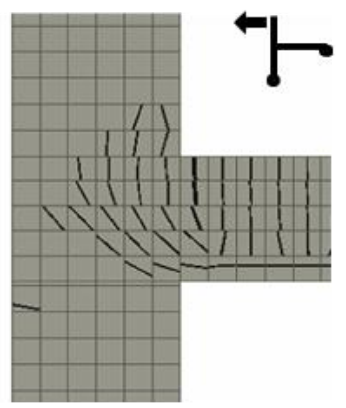

c)

Figure 9: a) Experimental crack pattern, b) numerical crack pattern for positive loading and c) numerical crack pattern for negative loading. 
Results of the experimental-numerical comparison confirm that the 3D nonlinear finite element model is able to adequately capture the experimental behavior of the specimen and, then, can be used for further numerical analysis devoted to investigating different detailing conditions as, for example, different amounts and positions of rebars in the beam.

\section{PARAMETRIC ANALYSIS}

A parametric analysis referred to the joint specimen numerically and experimentally analyzed before is carried out, by varying the longitudinal reinforcement area in the beam. Additional rebars have been considered and located in two different zones of the beam section, that is either externally to (E) or inside (I) the column core. For each position, two different amount of reinforcement have been considered. Referring to Fig. 10, the number associated with the letter $\mathrm{E}$ and $\mathrm{I}$ indicates the number of couples of $14 \mathrm{~mm}$ diameter bars added to the asbuilt arrangement. For example, solution E1 has one additional couple of $14 \mathrm{~mm}$ diameter bars for both the upper and lower reinforcement layers. Note that in all the three configurations, a symmetric reinforcement arrangement is considered.
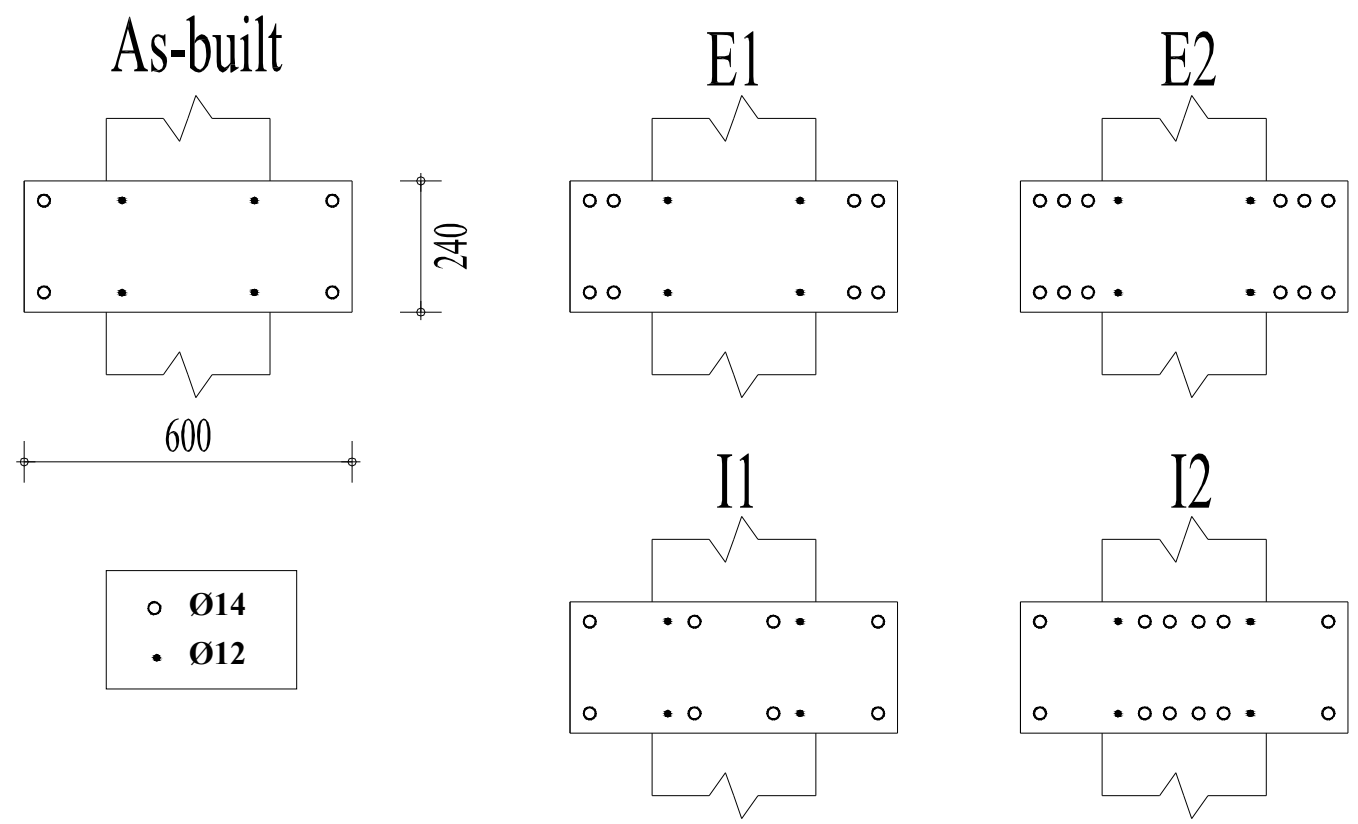

Figure 10: Different beam rebars arrangements for the parametric analysis.

The resulting reinforcement areas are reported in Tab. 1.

Starting from the 3D nonlinear FEM model of the as-built specimen, four additional FEM models were created by modifying the amount of steel longitudinal bars in the beam according to Fig. 10 and Tab. 1.

In order to evaluate the influence of the different bars' positions and amount on the postelastic behavior of the beam-column connections, nonlinear numerical simulations were carried out on the specimens E1, E2, I1 and I2. The numerical simulations provided the load-drift behavior and the damage mechanisms considering only positive loading in order to keep the computational effort under acceptable limits. 


\begin{tabular}{|c|c|c|c|c|}
\hline Specimen & $\begin{array}{c}\text { Bottom/Top } \\
\text { area } \\
\left(\mathrm{mm}^{2}\right)\end{array}$ & $\begin{array}{c}\text { Bottom/Top } \\
\text { area } \\
(\%)\end{array}$ & $\begin{array}{c}\text { Bottom/Top area } \\
\text { External } \\
(\%)\end{array}$ & $\begin{array}{c}\text { Bottom/Top area } \\
\text { Internal } \\
(\%)\end{array}$ \\
\hline As-built & 532 & 0.37 & 0.21 & 0.16 \\
\hline E1 & 838 & 0.58 & 0.43 & 0.16 \\
\hline E2 & 1144 & 0.79 & 0.64 & 0.16 \\
\hline I1 & 838 & 0.58 & 0.21 & 0.37 \\
\hline $\mathrm{I} 2$ & 1144 & 0.79 & 0.21 & 0.58 \\
\hline
\end{tabular}

Table 1: Reinforcement amounts for the parametric analysis.

As can be seen from Fig. 11 the addition of reinforcement generally improves the performance in terms of maximum load but not always in terms of ductility. In Tab. 2, the main results from the numerical simulations are summarized.

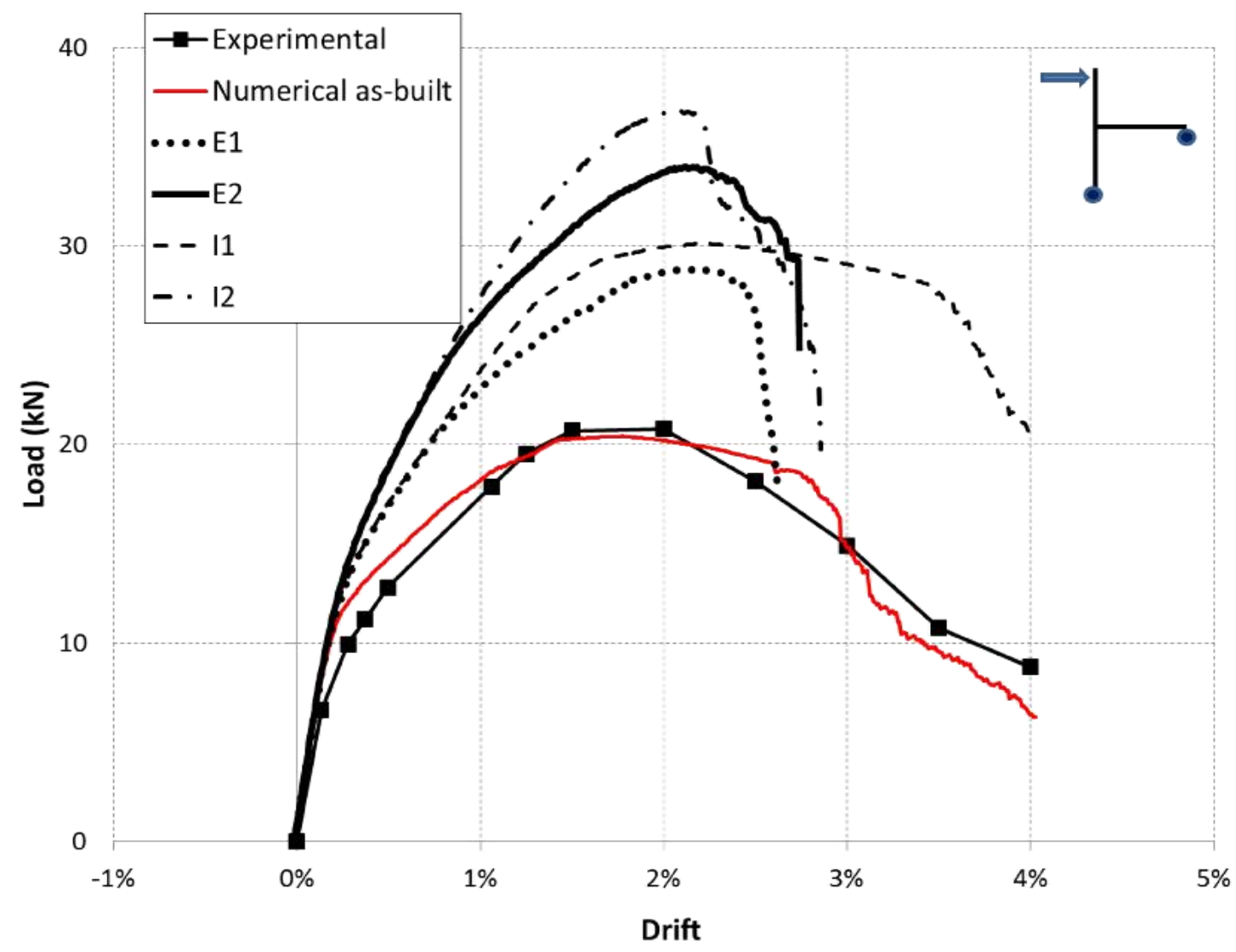

Figure 11: Load-drift curves from parametric analysis.

Note that the yielding points of the different cases have been derived directly from the FEM models by reading the drift values where the reinforcement stress attains values equal to the yielding strength $f_{y}$. For each of the models with increased amount of reinforcement, also the percentage increase with respect to the as-built model is reported $(\Delta \%)$.

The results show that comparing models with equal reinforcement amount, higher load values are found when the additional bars are placed inside the column core. In this case, lower slip phenomena occur, thus permitting a better exploitation of the rebars' strength. Indeed, 
41.2 and $66.5 \%$ increases are provided by E1 and E2 models while 46.9 and $80 \%$ increases are provided by I1 and I 2 models respectively.

Similar values of the deformation capacity values are found among the different models (giving a slight decrease with respect to the as-built model), with the exception of model I1 whose ultimate drift and ductility values are significantly higher than in the other models. Therefore, the configuration I1 appears preferable with respect to the other ones, determining a significant increase in terms of both maximum strength $(80 \%$ with respect to the as-built model) and, above all, ductility value (more than $90 \%$ increase).

\begin{tabular}{|c|c|c|c|c|c|c|c|c|c|}
\hline & \multicolumn{9}{|c|}{ Model } \\
\hline & \multirow{2}{*}{$\begin{array}{c}\begin{array}{c}\text { As-built } \\
\text { (numerical) }\end{array} \\
\text { Value } \\
\end{array}$} & \multicolumn{2}{|c|}{ E1 } & \multicolumn{2}{|c|}{ E2 } & \multicolumn{2}{|c|}{ I1 } & \multicolumn{2}{|c|}{ I 2} \\
\hline & & Value & $\Delta \%$ & Value & $\Delta \%$ & Value & $\Delta \%$ & Value & $\Delta \%$ \\
\hline $\boldsymbol{F}_{\boldsymbol{m a x}}[\mathrm{kN}]$ & 20.42 & 28.84 & 41.2 & 34.00 & 66.5 & 30.00 & 46.9 & 36.76 & 80.0 \\
\hline$d_{u}[\%]$ & 2.9 & 2.54 & -12.4 & 2.70 & -6.9 & 3.75 & 29.3 & 2.62 & -9.7 \\
\hline$d_{y}[\%]$ & 1.97 & 1.52 & -22.8 & 1.40 & -28.9 & 1.33 & -32.5 & 1.77 & -10.2 \\
\hline$\mu[-]$ & 1.47 & 1.67 & 13.6 & 1.93 & 31.3 & 2.82 & 91.8 & 1.48 & 0.7 \\
\hline
\end{tabular}

In order to better understand the resisting mechanism of the parametric models E and I, the crack width plots are reported in Fig. 12.

It is worth noting that these plots are set with a color scale able to properly highlight the crack width value over the whole beam-column intersection. To this end, the highest values are out of the scale and are represented by cyan color. The cyan areas reach a crack width higher than the maximum scale value $(0.7 \mathrm{~mm})$, being of the order of magnitude of $2 \mathrm{~mm}$.

The plots are relevant to the side views (exterior appearance of the crack pattern) and are taken at a drift value equal to $4 \%$, whereas achieved by the model, or to the maximum achieved value in case the analysis ended before $4 \%$ due to convergence problems. As can be seen, moving from the as-built model to E1 and I1 models and then to E2 and I2, a larger damage to the column can be observed. In fact, the higher flexural strength of the beam in E2 and I2 models shifts the collapse mechanism from a weak beam-strong column nearer to a balanced mechanism where the column is subjected to a higher flexural demand. However, only in the model I 2 the column reinforcement attains the yielding stress almost simultaneously to the beam rebars.

As a result, the models with higher steel amount (E2 and I2) show lower crack width values in the beam near the beam-column interface. Looking at the large difference in terms of ductility between the two models with additional rebars inside the column core (I1 and I2), the worst performance of 12 model can be related to the heavier damage suffered by the column attributable to the higher flexural demand to the column.

This conclusion is supported by the colormaps in Fig. 13 where the residual tensile strength is depicted at the load step corresponding to the peak loads observed for I1 and I2 models (the colormaps are relevant to a vertical section plane passing from the mid-side of the column). As already said, the tensile behavior of concrete has been simulated through a crack opening law (see Fig. 5b), where the residual tensile strength is dependent on the crack opening displacement. This means that the larger are the cracking opening displacements (crack sizes and, consequently, damage), the lower is the residual tensile strength. 
As can be seen, in model I1 the area with the lower residual tensile strength values (most damaged area) is essentially around the beam rebars partially affecting the column core. In model I2 (with larger beam reinforcement), this area has a larger extent due to the yielding of column longitudinal rebars.
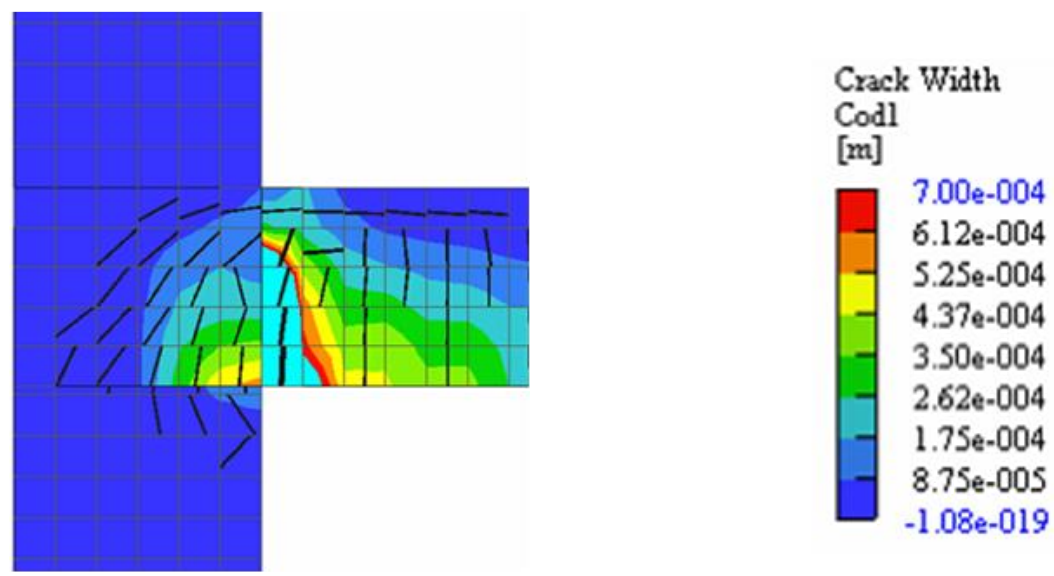

\section{As-built (@ 4.00\% drift)}

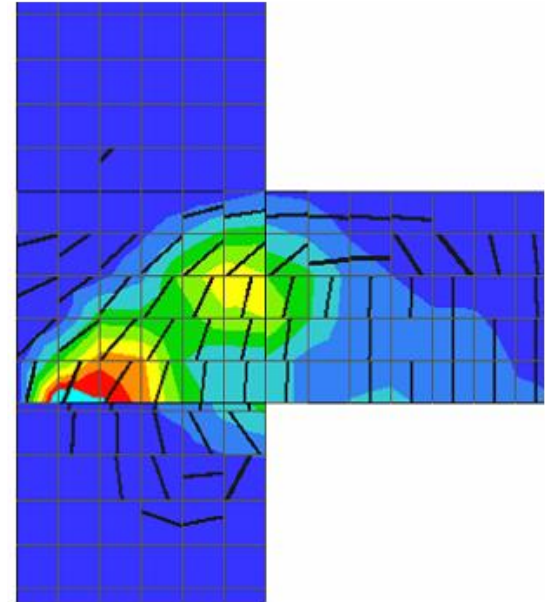

E1 (@ 2.62\% drift)

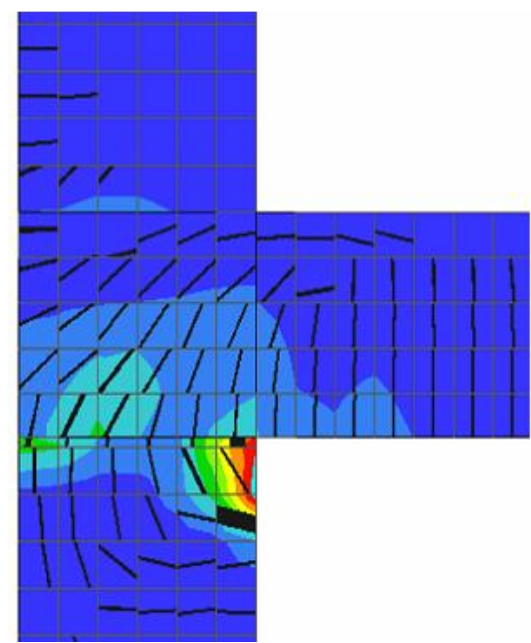

E2 (@2.78\% drift)

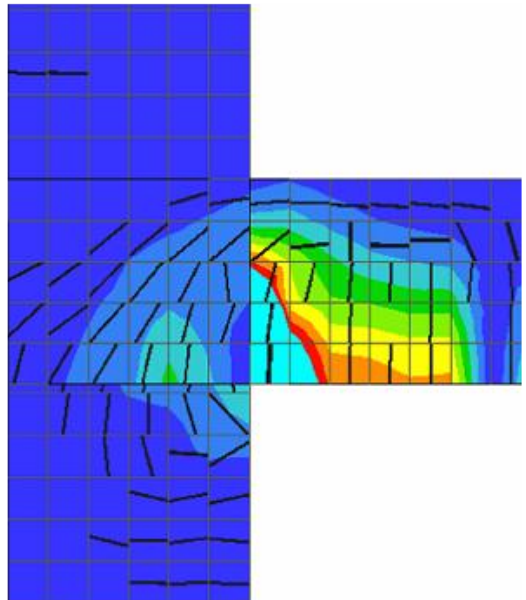

I1 (@ 4.00\% drift)

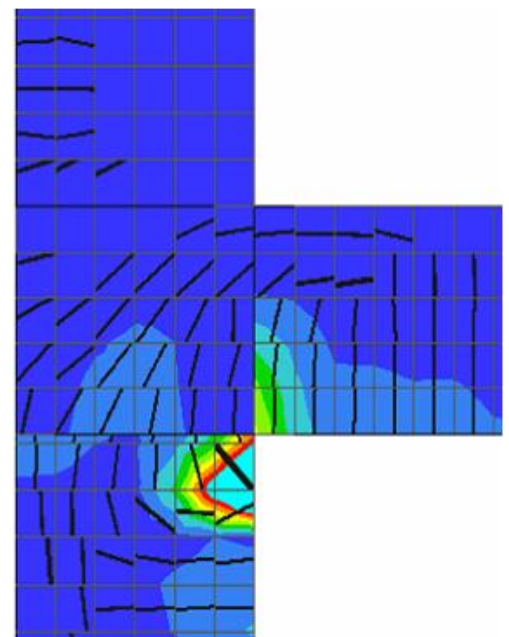

12 (@2.85\% drift)

Figure 12: Crack width plots in the four different models (side views). 
The heavier damage to the beam-column intersection of model I2 (especially in the rear part of the column, where the beam rebars are bent) causes a reduction of the tensile stress of beam and column rebars causing, in turn, a whole strength drop of the specimen and less favorable ductile performances.
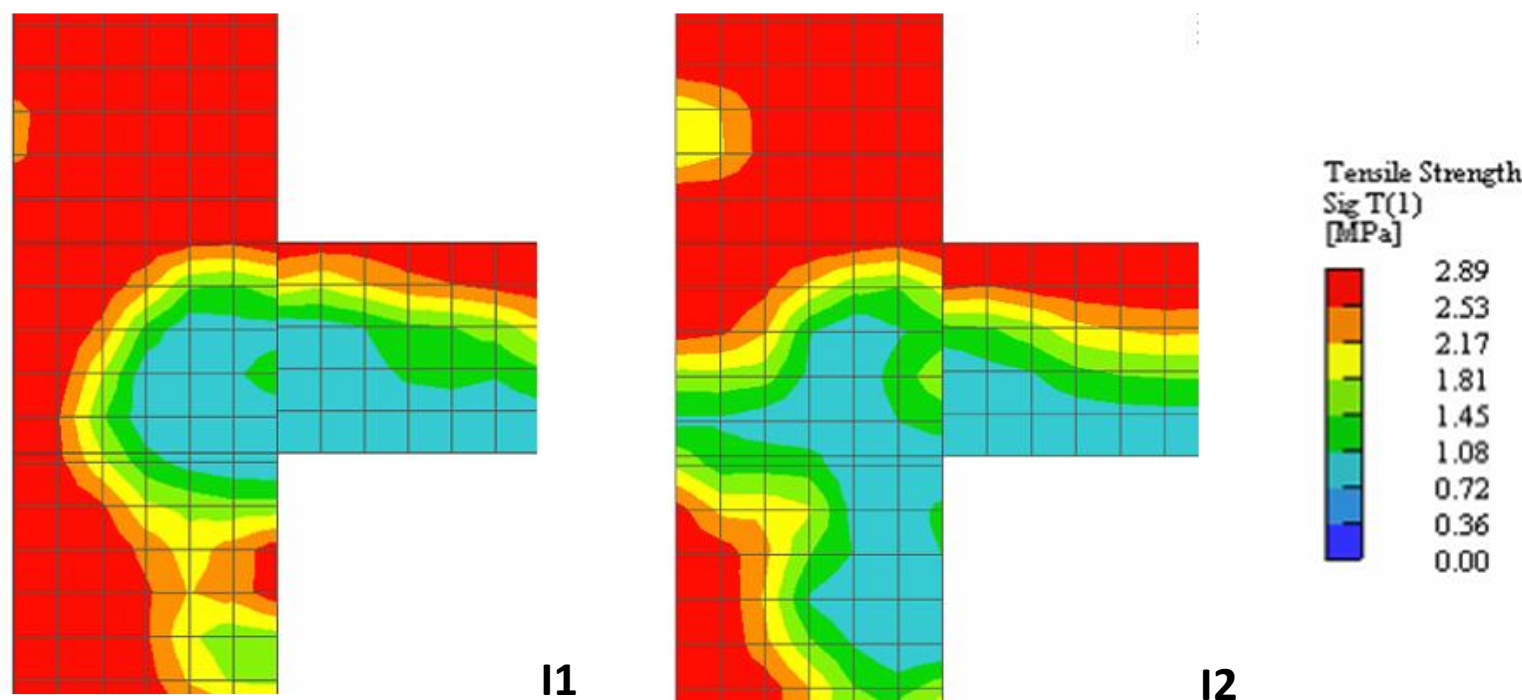

Figure. 13: Tensile strength field inside the column core at peak load.

\section{CONCLUDING REMARKS}

This study is focused on investigating the effect of the distribution of the beam rebars in wide beam-column joints. To this end, a parametric study based on nonlinear FEM analysis has been carried out. A detailed 3D nonlinear finite element model set-up with ATENA 3D software was built and calibrated aiming at reproducing the experimental results of a cyclic quasistatic test on a full-scale wide beam-column specimen.

The model was able to fully predict the nonlinear behavior of the specimen as well as to permit the execution of a parametric analysis in which other different models were created by modifying the number and the position of longitudinal reinforcement in the beam. Particularly, two different kinds of rebar positions were assumed. In the "E" models the additional rebars were placed outside the column core, in unconfined concrete while in the "I" models they were placed inside the column core, where some confinement due to the action of the hoops is present. Two levels of additional reinforcement area were assumed giving a total of four different models.

New numerical analyses on these four models revealed that, making a comparison for equal amount of beam reinforcement, E models have lower strength performance due to higher slip phenomena. In fact, most of the beam reinforcement bars are bonded in non-confined concrete causing a low bond strength. However, these models have also low ductility ratio due to the sudden deterioration and cracking at the beam sides. I models show better performance in terms of both strength and ductility. Indeed, the model with the lower amount of reinforcement offers the best solution because it provides $50 \%$ increment of the strength as well as an almost doubled value of the ductility ratio with respect the as-built specimen. This latter, be- 
cause the additional rebars are able to increase the beam flexure strength without triggering significant damage to the column and to the beam-column joint, which, in the I2 model (provided with a larger amount of reinforcement) suffer a heavier cracking near the beam intersection.

It can be concluded that whenever is possible, longitudinal beam rebars in wide beam-column joints have to be placed mostly inside the column core. The amount needs to be determined in such a way to avoid excessive flexural demand in the framing column, possibly leading to the failure of the joint panel. Further study is needed to identify these limits also taking into account the shape factor of the beam-column intersection.

\section{ACKNOWLEDGEMENTS}

The work reported in this article was carried out within the framework of the DPC-ReLUIS 2014-2016 Project, Research Line "Reinforced Concrete Structures", WP1.3 "Capacity of Joints".

\section{REFERENCES}

[1] Masi, A., Mucciarelli, M., Chiauzzi, L., De Costanzo, G., \& Loperte, G. (2014). Emergency preparedness activities during an ongoing seismic swarm: the experience of the 2011-2012 Pollino (Southern Italy) sequence. Bollettino di Geofisica Teorica ed Applicata. Volume 55, Issue 3, 1 December 2014, Pages 665-682

[2] Masi, A., Santarsiero, G., Mossucca, A., Nigro, D., (2014). Influence of axial load on the seismic behavior of RC beam-column joints with wide beam. 2014 2nd International Conference on Energy Material, Chemical Engineering and Mining Engineering, EMCEM 2014. Wuhan. https://doi.org/10.4028/www.scientific.net/AMM.508.208

[3] Masi A., Santarsiero, G. (2013). Seismic Tests on RC Building Exterior Joints with Wide Beams. Advanced Materials Research Vol. 787 (2013) pp 771-777.

[4] Masi A., Santarsiero G., Mossucca A., and Nigro D. (2016) Viable seismic strengthening solutions for RC wide beam-column joints. Applied Engineering, Materials and Mechanics: pp. 229-237.

[5] Masi, A., Santarsiero, G., \& Nigro, D. (2013). Cyclic Tests on External RC BeamColumn Joints: Role of Seismic Design Level and Axial Load Value on the Ultimate Capacity. Journal of Earthquake Engineering, 17(1), 110-136. https://doi.org/10.1080/13632469.2012.707345

[6] Masi, A., Santarsiero, G., Lignola, G. P., \& Verderame, G. M. (2013). Study of the seismic behavior of external RC beam-column joints through experimental tests and numerical simulations. Engineering Structures, 52, 207-219. https://doi.org/10.1016/j.engstruct.2013.02.023

[7] Santarsiero, G., \& Masi, A. (2015). Seismic performance of RC beam-column joints retrofitted with steel dissipation jackets. Engineering Structures, 85, 95-106. https://doi.org/10.1016/j.engstruct.2014.12.013 
[8] Cervenka Consulting, 2000-2014. ATENA Program Documentation, Part 1, ATENA Theory Manual. Praha.

[9] Pukl, R.a, Jansta, M.a, Červenka, J.a, Vořechovský, M.b, Novák, D.b, Rusina, R.b (2006) Spatial variability of material properties in nonlinear computer simulation. Computational Modelling of Concrete Structures - Proceedings of EURO-C 2006 2006, Pages 891-896 EURO-C 2006 Conference; Mayrhofen, Tyrol; Austria; 27 March 2006 through 30 March 2006; Code 88426.

[10] Pryl, D., Pukl, R., Cervenka, J. (2012) Modelling high-cycle fatigue of concrete specimens in three point bending. Proceedings of the 3rd International Symposium on LifeCycle Civil Engineering, IALCCE 2012 Life-Cycle and Sustainability of Civil Infrastructure Systems - Pages 1303-1306. Vienna; Austria; 3 October 2012 through 6 October 2012; Code 93181

[11] MC90. CEB-FIP Model Code 1990. Comité Euro-International du Béton; 1993.

[12] Panagiotakos T.B., Fardis M.N.: Deformation of reinforced concrete members at yielding and ultimate. ACI Structural Journal, 2001. 98(2), 135-148.

[13] Chen, W.F, Saleeb, A.F. (1982) - Constitutive Equations For Engineering Materials, John Willey \\& Sons, ISBN 0-471-09149-9.

[14] Remmel G. Zum Zug- und Schubtragverhalten von Bauteilen aus hochfestem Beton. DAfStb, Heft 444. Beuth Verlag, Berlin; 1994.

[15] Santarsiero G., Masi A., Seismic behavior of external RC wide beam-column joints through experimental tests and numerical simulations. Submitted to Engineering Structures.

[16] Masi, A., Digrisolo, A., \& Santarsiero, G. (2014). Concrete Strength Variability in Italian RC Buildings: Analysis of a Large DataBase of Core Tests. Applied Mechanics and Materials, 597, 283-290. https://doi.org/10.4028/www.scientific.net/AMM.597.283 